\title{
Systemic thrombolysis in a patient with massive pulmonary embolism and recent glioblastoma multiforme resection
}

\author{
Joshua Lampert, ${ }^{1}$ Behnood Bikdeli, ${ }^{2}$ Philip Green, ${ }^{3}$ Matthew R Baldwin ${ }^{4}$
}

'Department of Internal

Medicine, Columbia University Medical Center, New York City, New York, USA

${ }^{2}$ Division of Cardiology, Columbia University Medical

Center, New York, NY

${ }^{3}$ Division of Cardiology, Columbia University Medical

Center, New York, NY

${ }^{4}$ Division of Pulmonary and Critical Care Medicine, Columbia University College of Physicians and Surgeons, New York, NY

\section{Correspondence to}

Dr Joshua Lampert,

jml9026@nyp.org

Accepted 10 November 2017

\section{SUMMARY}

While trials of systemic thrombolysis for submassive and massive pulmonary embolism (PE) report intracranial haemorrhage $(\mathrm{ICH})$ rates of $2 \%-3 \%$, the risk of $\mathrm{ICH}$ in patients with recent brain surgery or intracranial neoplasm is unknown since these patients were excluded from these trials. We report a case of massive PE treated with systemic thrombolysis in a patient with recent neurosurgery for an intracranial neoplasm. We discuss the risks and benefits of systemic thrombolysis for massive PE in the context of previous case reports, prior cohort studies and trials, and current guidelines. There may be times when the immediate risk of death from massive PE outweighs the risk of ICH from systemic thrombolysis, even when guideline-listed major contraindications exist. This case provides an example of how the haemodynamic benefit of systemic thrombolysis outweighed the impact of $\mathrm{ICH}$ in a patient who had undergone recent neurosurgical resection of a glioblastoma multiforme tumour.

\section{BACKGROUND}

Massive pulmonary embolism (PE) is defined by systemic arterial hypotension and cardiogenic shock from right ventricular failure due to an obstructive embolism. Systemic arterial hypotension is defined as a systolic arterial pressure $<90 \mathrm{~mm}$ $\mathrm{Hg}$ or a drop in systolic pressure $>40 \mathrm{~mm} \mathrm{Hg}$ for $>15 \mathrm{~min}$. Shock is defined by tissue hypoperfusion, presenting as hypoxia, altered mental status, oliguria or cool extremities. ${ }^{1}$ In-hospital mortality in patients with massive PE ranges from 15\% for those with arterial hypotension to $65 \%$ for those with cardiac arrest. ${ }^{2}$ In two separate meta-analyses of randomised controlled trials that included patients with massive PE, systemic thrombolysis reduced the risk of in-hospital death by approximately $50 \% .^{3}{ }^{4}$ However, this mortality benefit is offset by major bleeding in approximately $10 \%$ of patients, with 2\%-3\% having intracranial haemorrhage (ICH). ${ }^{6}$ The 2016 American College of Chest Physicians (ACCP) Guidelines and Expert Panel Report for Antithrombotic Therapy for VTE Disease lists structural intracranial disease, recent brain surgery, prior $\mathrm{ICH}$ and ischaemic stroke within 3 months as major contraindications for thrombolytic therapy due to an increased risk of ICH with systemic thrombolysis. ${ }^{7}$ The 2011 American Heart Association (AHA) Scientific Statement and 2013 American College of Cardiology Foundation/AHA Task Force on Practice Guidelines list known malignant intracranial neoplasm and brain or spinal canal surgery within 2 months as absolute contraindications to thrombolysis for treatment of PE and ST-elevation myocardial infarction. ${ }^{8}{ }^{9}$ The Neurocritical Care Society does not provide guidelines for treatment of venous thromboembolism (VTE). While the ACCP guidelines note that the more severe the hypotension, the more compelling the indication for systemic thrombolysis, there are no specific recommendations to guide weighing the risks of ICH versus worsening circulatory shock in patients with massive PE and these major contraindications to thrombolysis. This is likely due to the fact that the risk of $\mathrm{ICH}$ in patients with these contraindications is unknown since they have traditionally been excluded from thrombolysis trials for acute PE and myocardial infarction. 51011

\section{CASE PRESENTATION}

A 54-year-old woman presented to the emergency department with acute-onset pleuritic chest pain for 2 days and a tight sensation in her left calf. One month prior to presentation, she underwent neurosurgical resection of a right frontal lobe glioblastoma multiforme (GBM), and had postoperative left-sided hemiparesis. She had been discharged to a subacute rehabilitation facility where she did not receive VTE prophylaxis. At presentation, she was tachycardic (110 beats/min), normotensive (118/60 mm Hg), tachypnoeic (26 breaths/min) and hypoxaemic (peripheral capillary oxygen saturation $\left(\mathrm{SpO}_{2}\right)$ of $90 \%$ while breathing ambient air). The ECG showed sinus tachycardia and serum cardiac troponin-T was $0.1 \mathrm{ng} / \mathrm{mL}$ (upper limit of normal $0.01 \mathrm{ng} / \mathrm{mL}$ ). CT pulmonary angiography (CTPA) showed large emboli in the right pulmonary artery and the right segmental and subsegmental branches with additional small emboli in the left segmental pulmonary artery branches (figure 1A). She was started on anticoagulation for acute PE with an 80 units/kg intravenous bolus of unfractionated heparin followed by an 18 units/kg/hour infusion, and was admitted to the hospital intermediate care unit.

Eight hours later, she acutely developed hypotension to $50 / 30 \mathrm{~mm} \mathrm{Hg}$ and worse hypoxaemia $\left(\mathrm{SpO}_{2} 70 \%\right.$ on supplemental oxygen at $15 \mathrm{~L} / \mathrm{min}$ delivered through a non-rebreather facemask). Her 


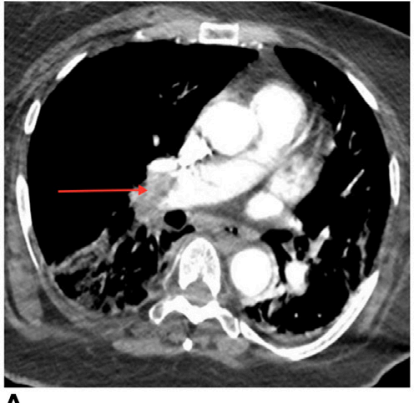

$\bar{A}$

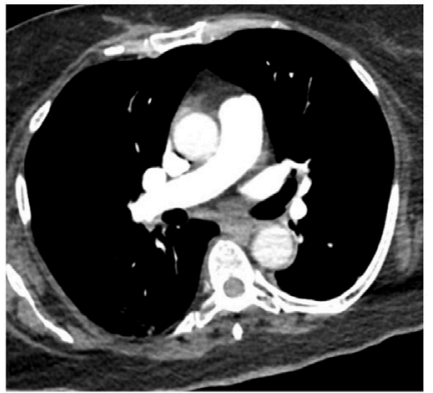

B
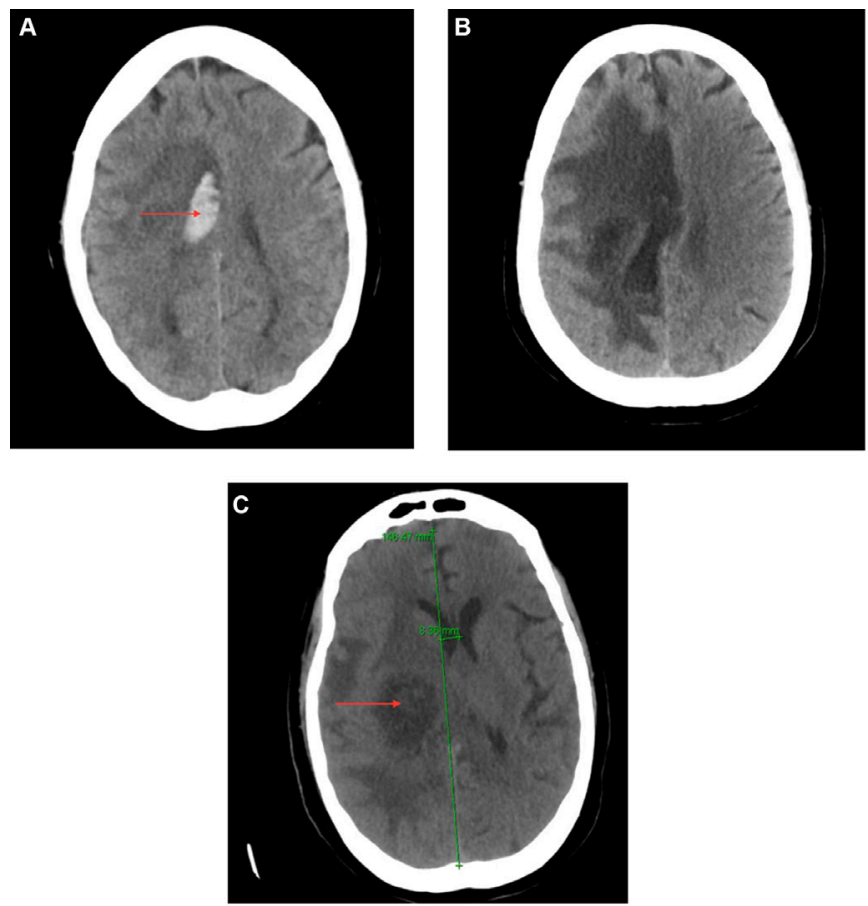

Figure $3 \mathrm{CT}$ of head demonstrating haemorrhage into resection site. (A) Intracranial haemorrhage into resection cavity (red arrow) 3 hours after thrombolysis. (B) Evolution of haemorrhage stable on follow-up without neurosurgical intervention 3 days after intracranial haemorrhage was diagnosed. (C) Follow-up CT 6 months after discharge demonstrating glioblastoma multiforme (GBM) progression (red arrow) and midline shift (green line) with resolution of haemorrhage.

infusion over 2 hours and transferred the patient to the intensive care unit. Within 3 hours, her circulatory shock resolved, norepinephrine was weaned off, and her $\mathrm{SpO}_{2}$ improved to $98 \%$ on nasal cannula at $2 \mathrm{~L} / \mathrm{min}$. A head CT obtained 3 hours after t-PA initiation revealed an acute $3 \times 1.4 \mathrm{~cm}$ right frontal lobe haemorrhage within the resection cavity with a $4 \mathrm{~mm}$ midline shift (figure 3A) (a postoperative head CT from 1 month prior had a $3 \mathrm{~mm}$ midline shift).

Unfractionated heparin infusion was discontinued upon initiating t-PA and was not resumed due to acute $\mathrm{ICH}$. An inferior vena cava (IVC) filter was placed after a distal left popliteal occlusive thrombus was visualised by ultrasonography with Doppler. Repeat head CT after 3 days showed no further ICH nor midline shift (figure 3B). She did not develop any new neurological deficits at any time. One day after thrombolysis, echocardiography demonstrated normal right ventricular function and no evidence of intracardiac thrombus. Four days later, CTPA showed near complete resolution of the large pulmonary emboli with residual small emboli in the right upper and left lower lobar arteries (figure 1B). She was discharged to a postacute care facility 6 days later without a need for supplemental oxygen. The IVC filter was left in situ. Two weeks later, a head CT showed resolution of the haemorrhage, and she was started on therapeutic enoxaparin at $1 \mathrm{mg} / \mathrm{kg}$ subcutaneously every 12 hours.

Medical history: GBM complicated by left hemiparesis and seizures status post-tumour resection 1 month prior to presentation, obesity, hypertension, left breast cyst removal and vaginal cyst removal.

Social history: Since being discharged from the hospital after brain surgery, she resided at a rehabilitation facility learning how to cope with her left hemiparesis and basic activity of daily living 
dependence. She is unemployed and has a 42 pack-year smoking history without any illicit drug or supplement use.

Family history: There is no significant family history.

\section{OUTCOME AND FOLLOW-UP}

The patient survived and was discharged 6 days after decompensation without any new neurological deficits. She remained clinically stable until 6 months later when she presented with altered mental status and was found to have recurrence of the GBM (figure 3C). She was discharged to inpatient hospice and died 8 months after being treated for her massive PE.

\section{DISCUSSION}

This case demonstrates that it is reasonable to consider thrombolysis as a therapeutic option for massive PE, even in a patient with recent neurosurgical resection of an intracranial tumour. We considered emergent surgical pulmonary embolectomy and catheter-directed thrombolysis, but decided to administer intravenous t-PA at the bedside for several reasons. Most importantly, we wanted to minimise time to treatment. We were concerned that if the thrombus in the right atrium and right ventricle embolised to the pulmonary artery, the patient might suffer a cardiac arrest since she was already in refractory circulatory shock in spite of a high dose of norepinephrine therapy. Second, her pre-existing left-sided hemiparesis would make rehabilitation from embolectomy surgery that involves a median sternotomy and cardiopulmonary bypass challenging. We also opted not to pursue catheter-directed thrombolysis or surgery because it would have delayed time to treatment. Third, we hypothesised that the patient's resection cavity could potentially act as a reservoir for haemorrhage and minimise cerebral swelling or midline shift. We could have, but did not consider, half-dose thrombolysis, which has been shown to be associated with less bleeding and comparable efficacy for treatment of PE in a retrospective cohort study and phase II trial. ${ }^{12-14}$

The patient developed an $\mathrm{ICH}$ into the resection cavity but never developed any symptoms or new neurological deficits. The head CT showed a midline shift of $4 \mathrm{~mm}$, which was only $1 \mathrm{~mm}$ greater than her baseline shift of $3 \mathrm{~mm}$ on a head CT from 1 month prior. There is a validated ICH risk score based on Glasgow Coma Scale, age, infratentorial versus supratentorial origin, and presence of intraventricular haemorrhage that ranges from 0 to 6 , with increasing scores predicting a higher risk of 30 -day mortality and functional deficit at 12 months. ${ }^{15-17}$ The patient had an $\mathrm{ICH}$ risk score of 0 , which predicted a $<3 \%$ risk of 30-day mortality and none-to-mild functional deficit at 12 months. In a retrospective population-based study of Finnish patients with $\mathrm{ICH}$, those with midline shifts of $1-5 \mathrm{~mm}$ and
6-24 mm had a 2.7 and 13.5 greater odds of 30-day mortality compared with patients with ICH without midline shift, respectively. ${ }^{18}$ While the generalisability of these data to this patient who haemorrhaged into a postsurgical frontal lobe resection cavity in the setting of thrombolysis is arguable, the minimal new midline shift, lack of new neurological sequelae and survival to hospital discharge are consistent with clinical outcomes in patients with de novo ICH.

Thrombolytic safety concerns first arose after the Gruppo Italiano per lo Studio della Streptochinasi nell'Infarto Miocardico (GISSI) trial showed that streptokinase reduced in-hospital mortality from acute myocardial infarction by $18 \% .{ }^{19}$ From the 1986 GISSI trial through the 2014 Pulmonary Embolism Thrombolysis (PEITHO) trial that showed tenecteplase for treatment of intermediate-risk PE increased the risk of major haemorrhage and stroke without improving mortality, no patients with recent brain surgery, prior ICH or ischaemic stroke within 3 months have been included in any major thrombolytic therapy trials. ${ }^{245101120}$ There are unlikely to be any future trials of systemic thrombolysis for massive PE in patients with these major contraindications to thrombolysis for several reasons. First, patients with massive PE and major contraindications to thrombolysis are rare and difficult to identify. Accordingly, recruiting enough patients to evaluate the potential benefit versus harm of thrombolysis would require a large multicentre study with intensive screening over a long period of time. Second, obtaining informed consent in a timely fashion that would not potentially cause harm due to delay in treatment would be difficult given that surrogate consent would most likely be needed since patients would lack capacity to provide consent in the setting of hypotension, shock or cardiac arrest. Lastly, there is an arguable lack of clinical equipoise for such a trial given the plausible increased risk of $\mathrm{ICH}$ with systemic thrombolysis in these patients with pre-existing intracranial pathology.

There are four prior published case reports of successful systemic thrombolysis for massive $\mathrm{PE}$ without $\mathrm{ICH}$ in patients with major contraindications due to intracranial pathology (table 1). Two cases had prior haemorrhagic strokes, ${ }^{21} 22$ one case had a $\mathrm{GBM},{ }^{23}$ and one case had recent neurosurgery for resection of a GBM. ${ }^{24}$ In all but one case, the patients had cardiac arrest from massive PE, which makes the decision to administer systemic thrombolysis easier since the risk of death without such therapy after cardiac arrest is so high. Our case is a notable addition to the literature insofar as our patient had not yet arrested when thrombolysis was administered, and our patient remained asymptomatic from ICH due to the fact that the blood accumulated in the pre-existing frontal lobe resection cavity. These cases, while potentially susceptible to positive result publication

Table 1 Case reports of thrombolysis with t-PA in massive PE despite intracranial guideline contraindication

\begin{tabular}{|c|c|c|c|c|c|c|c|}
\hline Author reference & $\begin{array}{l}\text { Publication } \\
\text { year }\end{array}$ & $\begin{array}{l}\text { t-PA } \\
\text { indication }\end{array}$ & Contraindication & Clinical scenario & $\begin{array}{l}\text { Patient age } \\
\text { (years) }\end{array}$ & Thrombolytic dose & Patient outcomes* \\
\hline Han et $a l^{23}$ & 2006 & $\mathrm{PE}$ & GBM & Hypotension/hypoxia & 72 & $\begin{array}{l}100 \mathrm{mg} \text { alteplase over } \\
2 \text { hours }\end{array}$ & GI bleed on warfarin \\
\hline Koroneos et $a l^{21}$ & 2007 & $\mathrm{PE}$ & Haemorrhagic CVA & Cardiac arrest & 53 & $\begin{array}{l}50 \mathrm{mg} \text { alteplase bolus } \\
\text { given twice }\end{array}$ & No adverse events \\
\hline Bottinor et $a l^{22}$ & 2014 & $\mathrm{PE}$ & Haemorrhagic CVA & Cardiac arrest & 60 & $\begin{array}{l}100 \mathrm{mg} \text { alteplase over } \\
2 \text { hours }\end{array}$ & $\begin{array}{l}\text { Rectal, vaginal and line-site } \\
\text { haemorrhage }\end{array}$ \\
\hline Bayram et $a l^{24}$ & 2014 & $\mathrm{PE}$ & $\begin{array}{l}\text { GBM and intracranial } \\
\text { surgery }\end{array}$ & Cardiac arrest & 63 & $50 \mathrm{mg}$ alteplase bolus & No adverse events \\
\hline
\end{tabular}

*All patients survived without any documented neurological or new functional deficits.

CVA, cerebrovascular accident; GBM, glioblastoma multiforme; GI, gastrointestinal; PE, pulmonary embolism; t-PA, tissue plasminogen activator. 
bias, suggest that thrombolytic therapy could be considered on a case-by-case basis in patients with massive PE and major contraindications due to intracranial pathology, and in whom cardiac arrest has occurred or seems imminent. In a registry study of 1001 patients from 204 medical centres with acute PE with overt or impending right heart failure, and where thrombolytic therapy was used in $48 \%$ of patients, in-hospital mortality ranged from $8 \%$ for those with right ventricular dysfunction, to $15 \%$ with arterial hypotension, to $25 \%$ with circulatory shock, to $65 \%$ with cardiac arrest. ${ }^{2}$ These data suggest that as hypotension progresses to circulatory shock or cardiac arrest, the immediate risk of death from not treating a PE with thrombolysis may become so high as to outweigh the risk of disability or death from ICH in patients with pre-existing intracranial pathology. ${ }^{2}$ These mortality data highlight a potential shifting of risk in regard to thrombolytic therapy for patients with massive PE and major contraindications. As hypotension progresses to circulatory shock or cardiac arrest, the risk of death or disability from ICH must be weighed against the immediate risk of death and need to administer prompt treatment.

In conclusion, this case provides an example of how the haemodynamic benefit of systemic thrombolysis outweighed the risk of clinical sequelae due to ICH in a patient who had undergone recent neurosurgical resection of a GBM. This case adds to prior similar cases that when taken together, suggest that thrombolysis for massive PE might be considered in patients with contraindicating intracranial pathology if cardiac arrest from circulatory shock has occurred or appears imminent.

\section{Learning points}

In a patient with circulatory shock from massive pulmonary embolism (PE) and recent brain surgery, the haemodynamic benefit of systemic thrombolysis outweighed the potential adverse consequences of intracranial haemorrhage (ICH).

- The resection cavity in this patient accommodated an $\mathrm{ICH}$ and may have obviated the need for neurosurgical decompression by decreasing midline shift.

- Future randomised controlled trials of thrombolysis in patients with massive PE and pre-existing intracranial pathology are unlikely to ever be conducted due to challenges with patient enrolment and clinical equipoise.

- Mortality increases substantially as patients with massive PE progress from hypotension, to circulatory shock, to cardiac arrest. It is therefore important to weigh the imminent risk of death from circulatory shock or cardiac arrest against the risk of death or disability from ICH when considering possible thrombolysis for those with pre-existing intracranial pathology.

Contributors JL, PG and MRB: manuscript, literature review, table, figures. BB: manuscript, literature review.

Funding National Heart, Lung, and Blood Institute (T32 HL007854).

Competing interests MRB is supported by NIH grants K23 AG045560 and UL1 TR001873. BB is supported by the National Heart, Lung, and Blood Institute, National Institutes of Health, through grant number T32 HL007854.

Patient consent Obtained.

Provenance and peer review Not commissioned; externally peer reviewed. (c) BMJ Publishing Group Ltd (unless otherwise stated in the text of the article) 2017. All rights reserved. No commercial use is permitted unless otherwise expressly granted.

\section{REFERENCES}

1 Kucher N, Goldhaber SZ. Management of massive pulmonary embolism. Circulation 2005;112:e28-32.

2 Kasper W, Konstantinides S, Geibel A, et al. Management strategies and determinants of outcome in acute major pulmonary embolism: results of a multicenter registry. J Am Coll Cardiol 1997;30:1165-71.

3 Wan S, Quinlan DJ, Agnelli G, et al. Thrombolysis compared with heparin for the initial treatment of pulmonary embolism: a meta-analysis of the randomized controlled trials. Circulation 2004:110:744-9.

4 Chatterjee S, Chakraborty A, Weinberg I, et al. Thrombolysis for pulmonary embolism and risk of all-cause mortality, major bleeding, and intracranial hemorrhage: a metaanalysis. JAMA 2014;311:2414-21.

5 Meyer G, Vicaut E, Danays T, et al. Fibrinolysis for patients with intermediate-risk pulmonary embolism. N Eng/ J Med 2014;370:1402-11

6 Goldhaber SZ, Visani L, De Rosa M. Acute pulmonary embolism: clinical outcomes in the International Cooperative Pulmonary Embolism Registry (ICOPER). Lancet 1999;353:1386-9.

7 Kearon C, Akl EA, Ornelas J, et al. Antithrombotic Therapy for VTE Disease: CHEST Guideline and Expert Panel Report. Chest 2016;149:315-52.

8 Jaff MR, McMurtry MS, Archer SL, et al. Management of massive and submassive pulmonary embolism, iliofemoral deep vein thrombosis, and chronic thromboembolic pulmonary hypertension: a scientific statement from the American Heart Association. Circulation 2011;123:1788-830.

9 O'Gara PT, Kushner FG, Ascheim DD, et al. 2013 ACCF/AHA quideline for the management of ST-elevation myocardial infarction: executive summary: a report of the American College of Cardiology Foundation/American Heart Association Task Force on Practice Guidelines. Circulation 2013;127:529-55.

10 An international randomized trial comparing four thrombolytic strategies for acute myocardial infarction. N Engl J Med 1993;329:673-82.

11 Piazza G, Hohlfelder B, Jaff MR, et al. A Prospective, Single-Arm, Multicenter Trial of Ultrasound-Facilitated, Catheter-Directed, Low-Dose Fibrinolysis for Acute Massive and Submassive Pulmonary Embolism: The SEATTLE II Study. JACC Cardiovasc Interv 2015:8:1382-92

12 Sharifi M, Vajo Z, Freeman W, et al. Transforming and simplifying the treatment of pulmonary embolism: "safe dose" thrombolysis plus new oral anticoagulants. Lung 2015;193:369-74

13 Wang $C$, Zhai Z, Yang Y, et al. Efficacy and safety of low dose recombinant tissue-type plasminogen activator for the treatment of acute pulmonary thromboembolism: a randomized, multicenter, controlled trial. Chest 2010;137:254-62.

14 Zhang Z, Zhai ZG, Liang LR, et al. Lower dosage of recombinant tissue-type plasminogen activator (rt-PA) in the treatment of acute pulmonary embolism: a systematic review and meta-analysis. Thromb Res 2014;133:357-63.

15 Hemphill JC, Bonovich DC, Besmertis L, et al. The ICH score: a simple, reliable grading scale for intracerebral hemorrhage. Stroke 2001:32:891-7.

16 Godoy DA, Piñero G, Di Napoli M. Predicting mortality in spontaneous intracerebral hemorrhage: can modification to original score improve the prediction? Stroke 2006;37:1038-44.

17 Hemphill JC, Farrant M, Neill TA. Prospective validation of the ICH Score for 12-month functional outcome. Neurology 2009;73:1088-94.

18 Fogelholm R, Murros K, Rissanen A, et al. Long term survival after primary intracerebral haemorrhage: a retrospective population based study. J Neurol Neurosurg Psychiatry 2005;76:1534-8.

19 Effectiveness of intravenous thrombolytic treatment in acute myocardial infarction. Gruppo Italiano per lo Studio della Streptochinasi nell'Infarto Miocardico (GISSI). Lancet 1986;1:397-402.

20 Van De Werf F, Adgey J, Ardissino D, et al. Single-bolus tenecteplase compared with front-loaded alteplase in acute myocardial infarction: the ASSENT-2 double-blind randomised trial. Lancet 1999;354:716-22.

21 Koroneos A, Koutsoukou A, Zervakis D, et al. Successful resuscitation with thrombolysis of a patient suffering fulminant pulmonary embolism after recent intracerebral haemorrhage. Resuscitation 2007;72:154-7.

22 Bottinor W, Turlington J, Raza S, et al. Life-saving systemic thrombolysis in a patient with massive pulmonary embolism and a recent hemorrhagic cerebrovascular accident. Tex Heart Inst J 2014:41:174-6.

23 Han S, Chaya C, Hoo GW. Thrombolytic therapy for massive pulmonary embolism in a patient with a known intracranial tumor. I Intensive Care Med 2006;21:240-5.

24 Bayram B, Oray Neşe Çolak, Korkmaz E, et al. Massive pulmonary embolism and cardiac arrest; thrombolytic therapy in a patient with recent intracranial surgery and glioblastoma multiforme. Am J Emerg Med 2014;32:1441.e1-3. 
Copyright 2017 BMJ Publishing Group. All rights reserved. For permission to reuse any of this content visit http://group.bmj.com/group/rights-licensing/permissions.

BMJ Case Report Fellows may re-use this article for personal use and teaching without any further permission.

Become a Fellow of BMJ Case Reports today and you can:

- Submit as many cases as you like

- Enjoy fast sympathetic peer review and rapid publication of accepted articles

Access all the published articles

- Re-use any of the published material for personal use and teaching without further permission

For information on Institutional Fellowships contact consortiasales@bmjgroup.com

Visit casereports.bmj.com for more articles like this and to become a Fellow 